\title{
Bimodal stimulation in children with inner ear malformation: One side cochlear implant and contralateral auditory brainstem implant
}

\author{
Merve Ozbal Batuk ${ }^{1}$ (D) | Betul Cicek Cinar $^{1}$ (D) | Mehmet Yarali $^{1}$ | Filiz Aslan ${ }^{1}$ | \\ Hilal Burcu Ozkan ${ }^{1}$ | Gonca Sennaroglu ${ }^{1}$ | Esra Yucel ${ }^{1}$ | Munir Demir Bajin ${ }^{2}$ | \\ Burcak Bilginer $^{3}$ | Levent Sennaroglu ${ }^{2}$
}

\author{
${ }^{1}$ Department of Audiology, Hacettepe \\ University Faculty of Health Sciences, \\ Ankara, Turkey \\ ${ }^{2}$ Department of Otorhinolaryngology, \\ Hacettepe University, Ankara, Turkey \\ ${ }^{3}$ Department of Neurosurgery, Hacettepe \\ University, Ankara, Turkey

\section{Correspondence} \\ Merve Ozbal Batuk, Department of \\ Audiology, Hacettepe University Faculty \\ of Health Sciences, 06100 Sinhiye/Ankara, \\ Turkey \\ Email: merveozbal@hotmail.com
}

\begin{abstract}
Objective: To determine audiological outcomes of children who use a cochlear implant $(\mathrm{Cl})$ in one ear and an auditory brainstem implant (ABI) in the contralateral ear. Design: Retrospective case review. Setting: Tertiary referral hospital. Participants: Twelve children followed with $\mathrm{Cl}$ and contralateral auditory brainstem implant ( $\mathrm{ABI}$ ) by Hacettepe University Department of Otorhinolaryngology and Audiology in Turkey. All children were diagnosed with different inner ear malformations with cochlear nerve aplasia/hypoplasia. $\mathrm{Cl}$ was planned in the ear with better sound detection during behavioural testing with inserted ear phones and with better $\mathrm{CN}$ as seen on MRI. Due to the limited auditory and speech progress with the cochlear implant, $A B I$ was performed on the contralateral ear in all subjects.

Main outcome measures: Audiological performance and auditory perception skills of children with cochlear nerve deficiency (CND) who use bimodal electrical stimulation with $\mathrm{Cl}$ and contralateral $\mathrm{ABI}$.

Results: Mean age of the subjects was $84.00 \pm 33.94$ months. Age at $\mathrm{Cl}$ surgery and $A B I$ surgery was $25.00 \pm 10.98$ months and $41.50 \pm 16.14$ months, respectively. However, hearing thresholds only with $\mathrm{Cl}$ and only with $\mathrm{ABI}$ did not reveal significant difference, and auditory perception scores improved with bimodal stimulation. The MAIS scores were significantly improved from unilateral $\mathrm{Cl}$ to bimodal stimulation $(P=.002)$. Pattern perception and word recognition scores were significantly higher with the bimodal condition when compared to $\mathrm{Cl}$ only and $\mathrm{ABI}$ only conditions.

Conclusion: Children with CND showed better performance with $\mathrm{Cl}$ and contralateral $\mathrm{ABI}$ combined. Depending on the audiological and radiological results, bimodal stimulation should be advised for children with CND.
\end{abstract}

\section{1 | INTRODUCTION}

Cochlear implantation $(\mathrm{Cl})$ is the most frequent surgical method used with an electronic device for individuals with severe to profound 
reports showing the benefits of $\mathrm{Cl}$ in IEM, $\mathrm{Cl}$ became an accepted procedure in this patient population. ${ }^{3}$ However, when the IEM are severe and occur with cochlear nerve (CN) or cochleovestibular nerve (CVN) deficiency or hypoplasia, the clinicians are faced with the dilemma of deciding between $\mathrm{Cl}$ and an auditory brainstem implantation $(\mathrm{ABI})$.

Paediatric $A B I$ indications were clearly defined in two groups in the first $A B I$ consensus meeting. The first group was definite congenital indications, including complete labyrinthine aplasia (Michel aplasia), cochlear aplasia, CN aplasia and cochlear aperture aplasia. The second group was possible congenital indications, including hypoplastic cochlea with cochlear aperture hypoplasia, common cavity and incomplete partition type I cases with or without $\mathrm{CN}$, the presence of a common CVN and the presence of hypoplastic $\mathrm{CN} .{ }^{4}$

Patients with hypoplastic $\mathrm{CNs}$ or thin, unbranched $\mathrm{CVNs}$ constitute the most controversial group in the $\mathrm{Cl}$ and $\mathrm{ABI}$ decision. ${ }^{5}$ Even in patients with confirmed $\mathrm{CN}$ hypoplasia or aplasia on magnetic resonance imaging (MRI), some auditory responses could be observed on certain frequencies during audiological evaluation in one or both ears, which is compatible with severe hearing loss. ${ }^{5,6}$ Cochlear implant users with hypoplastic $\mathrm{CN}$ or $\mathrm{CVN}$ have only a limited benefit and lag behind the cochlear implant users with normal $\mathrm{CN}$ or $\mathrm{CVN} .^{5,7}$ Another amplification option for these types of patients is the ABI, which improves environmental sound awareness, speech detection and language skills. ${ }^{5,8}$ Thus, for cases with limited benefit from $\mathrm{Cl}$, the application of contralateral $\mathrm{ABI}$ can be considered.

The first report of $\mathrm{Cl}$ with a contralateral $\mathrm{ABI}$ was presented by Peng et al $^{9}$ with nine adult NF-2 patients. The results of paediatric bimodal stimulation with $\mathrm{Cl}$ and the $\mathrm{ABI}$ in four children were reported by Friedman et al in $2018 .{ }^{10}$ With this understanding of the benefits of bimodal stimulation, the first child at our clinic was implanted with a contralateral $A B I$ in 2013. To date, 25 paediatric patients with various inner ear malformations have been implanted with a cochlear implant in one ear and an $A B I$ in the other ear in our clinic. In the current paper, we report the audiological findings of 12 paediatric bimodal implant users with both cochlear implants and auditory brainstem implants.

\section{2 | MATERIALS AND METHODS}

\section{1 | Ethical considerations}

The study was authorised by the Hacettepe University NonInterventional Clinical Research Ethics Board (GO 18/437).

\section{2 | Participants}

Twenty-five children with bilateral prelingual profound SNHL were implanted with a cochlear implant on one side and an $\mathrm{ABI}$ on the other side at the Hacettepe University Department of Otorhinolaryngology. Six subjects were implanted with a cochlear

\section{Keypoints}

- CN hypoplasia presents a challenge in the decision-making process concerning the choice of $\mathrm{Cl}, \mathrm{ABI}$, or $\mathrm{Cl}$ and $A B I$ together.

- Depending on the audiological and radiological results, bilateral stimulation should be advised for children with IEM and CN hypoplasia.

- In cases of hardly visible cochlear nerve, we have observed that children implanted with $\mathrm{Cl}$ and contralateral $\mathrm{ABI}$ showed better performance when compared to either device alone.

- Depending on our clinical experience contralateral $A B$ should be done within 12-18 months after $\mathrm{Cl}$.

implant and an $\mathrm{ABI}$ simultaneously. One subject was implanted with an $A B I$ initially and with a cochlear implant at a later date due to a reimbursement issue. The remaining 18 subjects were implanted with a cochlear implant initially and later with an ABI. Six out of the eighteen were excluded, one due to postoperative neurological problems and the remaining five due to their limited experience with $A B I s$. The remaining 12 children with severe IEM and bilateral profound hearing loss were included in this study. Simultaneous $\mathrm{Cl}$ and $A B I$ results have been submitted separately as another paper.

All subjects completed medical, audiological, and speech and language assessments, as well as temporal bone imaging preoperatively. The preoperative audiological evaluation was composed of auditory brainstem responses (ABR) and behavioural testing with and without hearing aids. The hearing thresholds were assessed preoperatively using inserted earphones and hearing aids in free field with age-appropriate behavioural methods, such as visual reinforcement audiometry or play audiometry. The $\mathrm{Cl}$ side was determined according to the results of behavioural responses and the status of the $\mathrm{CN}$ on magnetic resonance imaging (MRI). $\mathrm{Cl}$ was planned in the ear with better sound detection during behavioural testing with inserted ear phones and with better $\mathrm{CN}$ as seen on MRI. Clinical features of the subjects are given in Table 1.

All 12 subjects (five male and seven female) were initially implanted with a cochlear implant and then subsequently implanted with an ABI between January 2013 and November 2016 due to their limited progress in auditory perception skills. The preoperative audiological test results were not reported in the current study, and only audiological performance with the $\mathrm{Cl}$ and the $\mathrm{ABI}$ was retrospectively reviewed in this study. The data presented in this study were collected between January 2013 and July 2018.

\section{3 | Intraoperative and postoperative audiological measurements}

No major intraoperative complications were encountered during both $\mathrm{Cl}$ and $\mathrm{ABI}$ surgeries. Initial activation of the cochlear implant was 


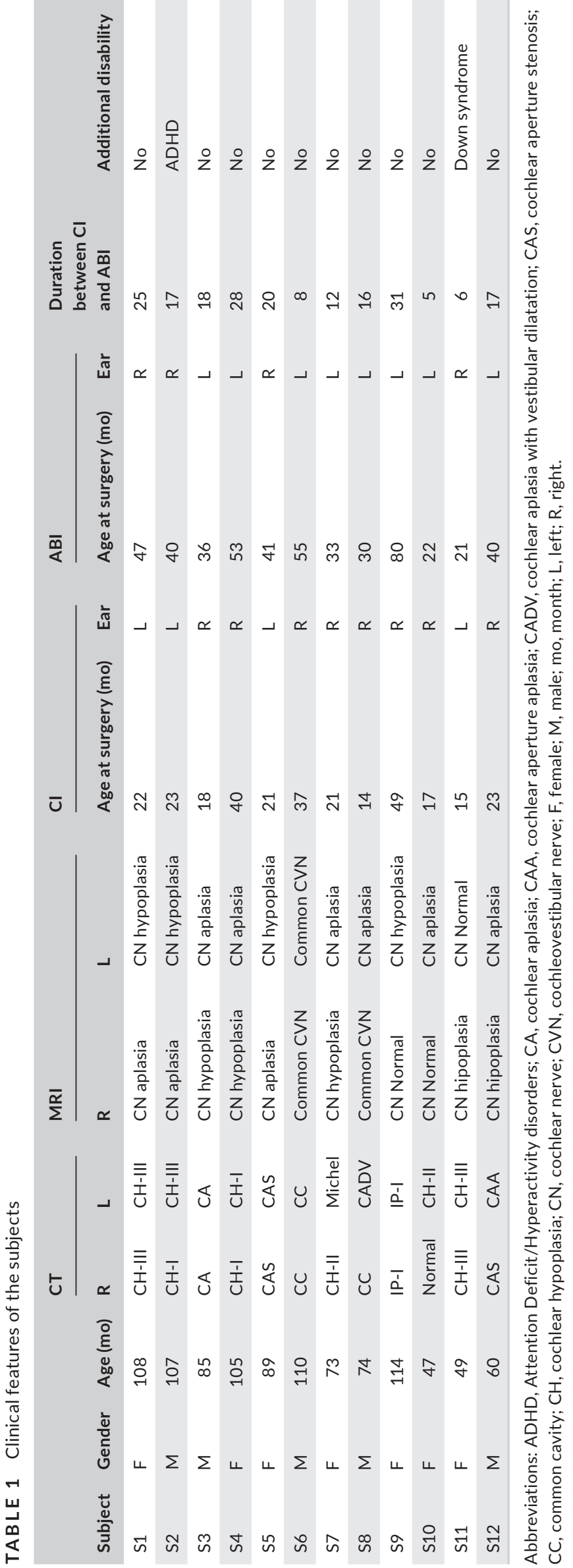

performed 2-4 weeks after $\mathrm{Cl}$ surgery in all subjects. The programming parameters were selected as default at initial fitting, and the minimum duration levels and pulse width values were increased during the follow-up visits due to hypoplastic $\mathrm{CN}$. After $\mathrm{Cl}$, all subjects were followed by the same audiologists. Due to the limited auditory and speech progress with the cochlear implant, $A B I$ was performed on the contralateral ear in all subjects. The limited progress with cochlear implants was evaluated by the experienced auditory implant team during the follow-up visits through auditory performance and improvement in auditory perception skills. The electrical ABR was used intraoperatively during the $A B I$ surgery to evaluate the placement of the $A B I$ electrode. The initial activation of the $A B I$ was executed four weeks after surgery with monitoring of the vital functions. Electrical impedances were measured in every programming session. Programming parameters of the $\mathrm{ABI}$ side and auditory/non-auditory sensations were recorded during each session. The follow-up programming visits were planned every two to three months in the first two years and every three months after the second year.

\subsection{Evaluation of the auditory perception skills}

Auditory perception tests used during the follow-up period contained the following test battery: Meaningful Auditory Integration Scale (MAIS), pattern perception test, word recognition test, Speech Intelligence Rating (SIR) and Category of Auditory Performance (CAP) scale. The MAIS is a parent-reported questionnaire that assesses the listening skills in children with hearing loss. Each item was rated together with parents and scored from 0 to $4(0=$ never, $1=$ rarely, 2 = occasionally, 3 = frequently and 4 = always), with a total score of 0 to $40 .{ }^{11}$ The CAP is a rating scale from 0 (no awareness of sound) to 7 (the use of telephone with a familiar speaker) in order to evaluate the hearing outcomes. ${ }^{12}$ The SIR measures the speech intelligibility and shows the overall progress in speech over time with a rating of 1 (unintelligible speech with a manual primary mode of communication) to 5 (understandable speech to all listeners). ${ }^{13}$ The pattern perception and word recognition tests were applied from the Children's Auditory Perception Skills Test in Turkish (CIAT) test battery. ${ }^{8}$ The pattern perception and word recognition tests were applied verbally in three different conditions: $\mathrm{ABI}$ only, $\mathrm{Cl}$ only and bimodal condition. All auditory perception tests were administered by the same experienced audiologist with a live voice during the follow-up visits.

\section{RESULTS}

\section{1 | Demographics}

Mean age of the subjects was $84.00 \pm 33.94$ months (range 60108 months). Age at $\mathrm{Cl}$ surgery was $25 \pm 10.98$ months (range 14-49 months), and age at $A B I$ surgery was $41.50 \pm 16.14$ months (range 21-80 months). Mean duration between $\mathrm{Cl}$ and implantation of the $\mathrm{ABI}$ was $16.91 \pm 8.32$ months (range 5-31 months). 
Two of the subjects were reimplanted due to facial nerve stimulation (FNS) (Subject \#6) or device failure (Subject \#3) in the $\mathrm{Cl}$ side. One subject (Subject \#8) was reimplanted with another implant from a different company at the request of the family due to insufficient performance with the previous implant in the $A B I$ side.

Except for one subject, all subjects used both $\mathrm{Cl}$ and $\mathrm{ABI}$ sound processors regularly. Subject \#6 refused to use the $\mathrm{Cl}$ processor after $\mathrm{ABI}$ surgery, complaining of not hearing with $\mathrm{Cl}$ as well as $\mathrm{ABI}$.

\section{2 | Intraoperative testing and audiological performance}

Electrical $A B R$ was performed intraoperatively during $A B I$ surgery in all subjects. The eABR results and programming parameters of the subjects are given in Table 2. Programming parameters were selected as default for strategy, rate and pulse width/duration at the initial fitting session of the $A B I$. For Cochlear ${ }^{\mathrm{TM}} A B I$ systems, the initial stimulation was performed in bipolar mode in order to avoid possible non-auditory stimulation. During follow-up, stimulation mode was changed to monopolar mode. The values of the pulse width/ duration/amplitude were not given in this paper due to the heterogeneity of the subjects. In case there was any non-auditory stimulation, these values were widened to avoid stimulation of any other cranial nerves.

Hearing thresholds with $\mathrm{Cl}$ only and $\mathrm{ABI}$ only are given in Table 3. Thresholds with $\mathrm{Cl}$ only were not assessed for Subject \#6 due to the subject not using the $\mathrm{Cl}$ processor and were reported as "not applicable" (NA) in Table 3. Subject \#11 was diagnosed with Down syndrome, and since it was not possible to evaluate thresholds with $\mathrm{Cl}$ and all thresholds with $\mathrm{ABI}$ due to her additional disability, this is reported as NA in Table 3.

\subsection{Non-auditory sensations in ABI side}

The mean number of active electrodes was found $67.62 \pm 17.49 \%$ (between 33.33\% and 93.33\%). The three causes of electrode deactivation were defined as non-auditory sensations, inadequate auditory stimulation and impedance/voltage problems. Non-auditory sensations were not observed in 1 (Subject \#8) out of 12 children. The observed non-auditory sensations were FNS (58.3\%), balance problems (8.3\%), gag reflex (8.3\%), and shoulder (25\%) or neck pain (8.3\%) in the remaining subjects. In 2 out of 12 children, more than 1 non-auditory sensation was observed, and the electrode was deactivated.

\section{4 | Auditory perception skills before and after ABI}

The MAIS scores were significantly improved from unilateral $\mathrm{Cl}$ to bimodal stimulation $(P=.002)$. Although all patients improved to $\leq 3$ in CAP scores after $\mathrm{Cl}$, their CAP scores increased to $\geq 4$

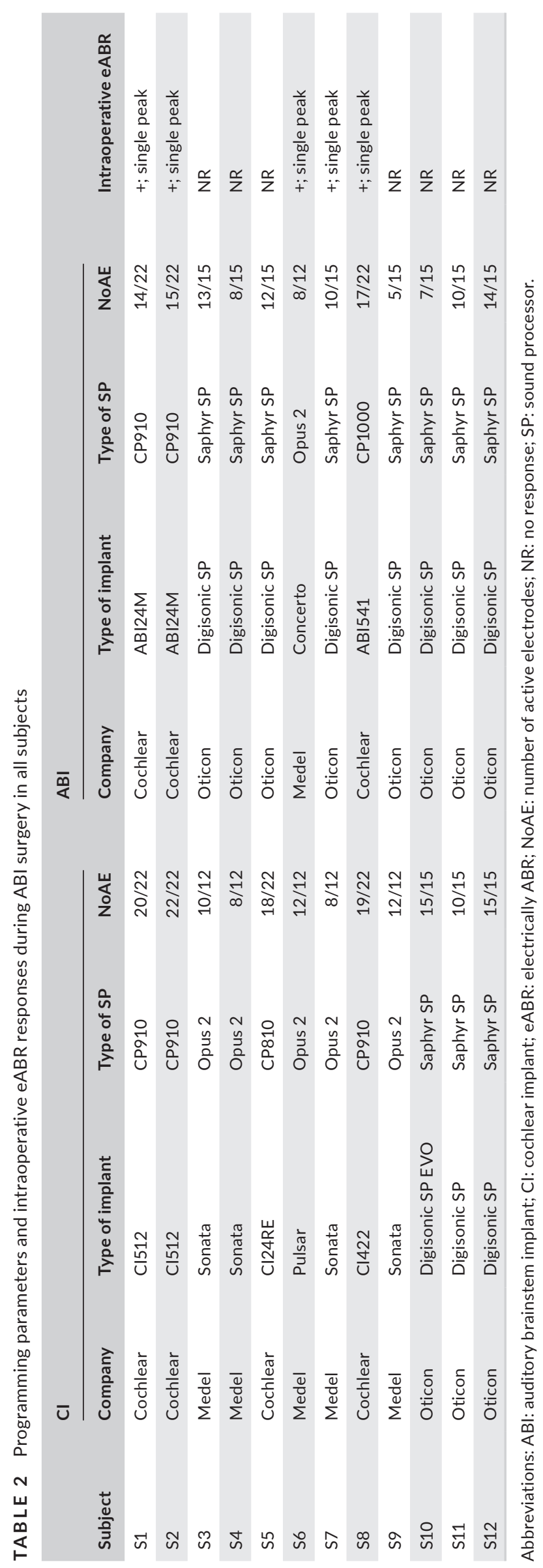


TABLE 3 Hearing thresholds with $\mathrm{Cl}$ and with $\mathrm{ABI}$

\begin{tabular}{|c|c|c|c|c|c|c|c|c|c|c|c|c|}
\hline Test frequency & S1 & S2 & S3 & S4 & S5 & S6 & S7 & S8 & S9 & S10 & S11 & $\mathrm{S} 12$ \\
\hline $500 \mathrm{~Hz}$ & 30 & 50 & 40 & 40 & 50 & NA & 45 & 50 & 30 & 35 & NA & 40 \\
\hline $2000 \mathrm{~Hz}$ & 25 & 55 & 35 & 45 & 60 & NA & 40 & 60 & 35 & 35 & NA & 50 \\
\hline $4000 \mathrm{~Hz}$ & 30 & 65 & 45 & 50 & 60 & NA & 40 & 55 & 40 & 40 & NA & 40 \\
\hline \multicolumn{13}{|c|}{ Thresholds with $\mathrm{ABI}$} \\
\hline $500 \mathrm{~Hz}$ & 40 & 35 & 30 & 40 & 55 & 35 & 35 & 50 & 30 & 45 & NA & 50 \\
\hline $1000 \mathrm{~Hz}$ & 35 & 30 & 40 & 35 & 55 & 35 & 35 & 55 & 30 & 50 & 60 & 55 \\
\hline $2000 \mathrm{~Hz}$ & 35 & 40 & 30 & 40 & 50 & 45 & 35 & 55 & 35 & 50 & 70 & 55 \\
\hline
\end{tabular}

Abbreviations: $\mathrm{ABI}$, auditory brainstem implant; $\mathrm{Cl}$, cochlear implant; $\mathrm{NA}$, not available; SAT, speech awareness threshold.

FIGURE 1 Category of Auditory Performance and Speech Intelligibility Rating scores before and after $\mathrm{ABI}$

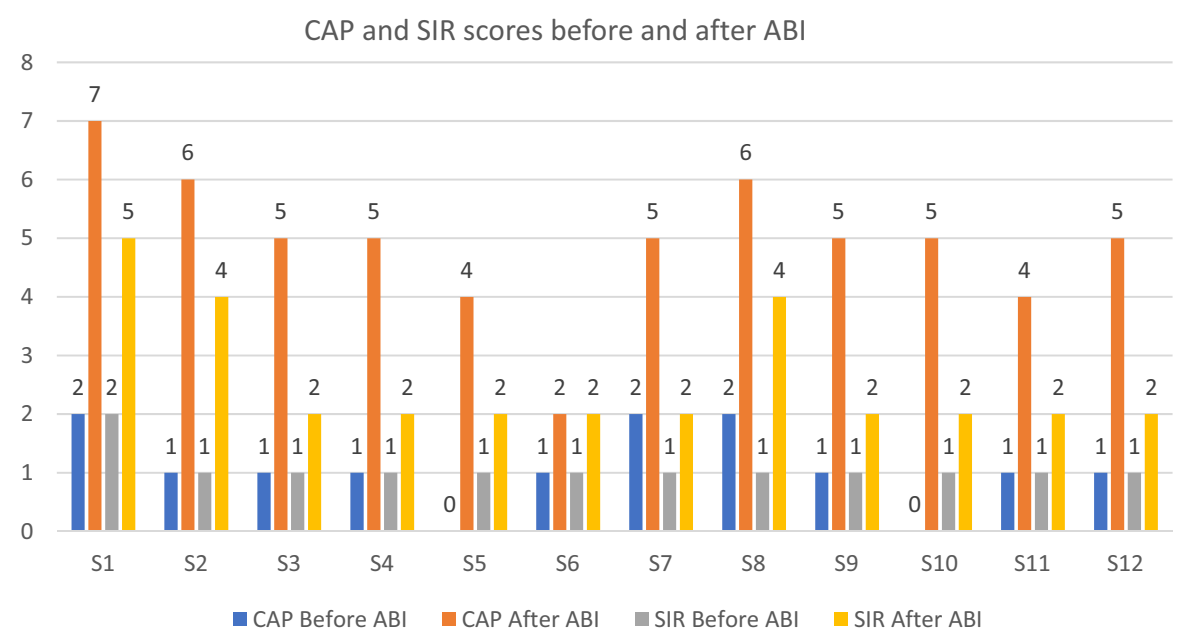

after $\mathrm{ABI}$ (Figure 1). There was a statistical improvement in CAP scores with bimodal stimulation $(P=.002)$. The speech intelligibility of all subjects advanced rapidly with the use of both $\mathrm{Cl}$ and $\mathrm{ABI}$ $(P=.001)$.

Pattern perception and word recognition scores were significantly higher with the bimodal condition when compared to $\mathrm{Cl}$ only and $\mathrm{ABI}$ only conditions. Pattern perception scores with $\mathrm{Cl}$ only, with $\mathrm{ABI}$ only and with bimodal conditions were $62.25 \pm 39.21$, $57.83 \pm 39.59$ and $84.91 \pm 24.83$, respectively. Word recognition scores with $\mathrm{Cl}$ only, with $\mathrm{ABI}$ only and with bimodal conditions were $33.00 \pm 14.14,25.25 \pm 18.38$ and $53.16 \pm 38.18$, respectively. As seen in Table 4, pattern perception scores increased in the bimodal condition, even when the scores were significantly lower in both $\mathrm{Cl}$ only $(P=.017)$ and $\mathrm{ABI}$ only $(P=.018)$ conditions. Word recognition scores were also significantly higher in the bimodal condition when compared to $\mathrm{Cl}$ only $(P=.012)$ and $\mathrm{ABI}$ only $(P=.008)$ conditions. Despite pattern perception scores not being significantly different $(P=.680)$, the word recognition scores were significantly higher $(P=.027)$ in the $\mathrm{Cl}$ only condition than in the $\mathrm{ABI}$ only condition.

\subsection{Factors influencing auditory performance with $A B I$}

It was found that hearing performance with $A B I$ was negatively correlated with chronological age $(P=.032 ; r=-.618)$ and the age at $A B I$ $(P=.039 ; r=-.601)$. There was a positive correlation between hearing performance with $\mathrm{ABI}$ and bimodal pattern perception scores $(P=.056 ; r=-.564)$. The postoperative MAIS scores were positively correlated with pattern perception and word recognition scores in all three conditions.

\section{4 | DISCUSSION}

Cochlear hypoplasia with hypoplastic cochlear aperture, the presence of an unbranched CVN and hypoplastic CN constitute a dilemma for decision-making for $\mathrm{Cl}$ and $\mathrm{ABI}$ selection. ${ }^{4,5}$ Previous studies report poor outcomes for IEMs with $\mathrm{CN}$ deficiency with $\mathrm{Cl}^{6,14-16}$ Despite the limited progress with $\mathrm{Cl}$ in patients with hypoplastic $\mathrm{CN}$, this was not considered as a contraindication for $\mathrm{Cl}^{17}$ 


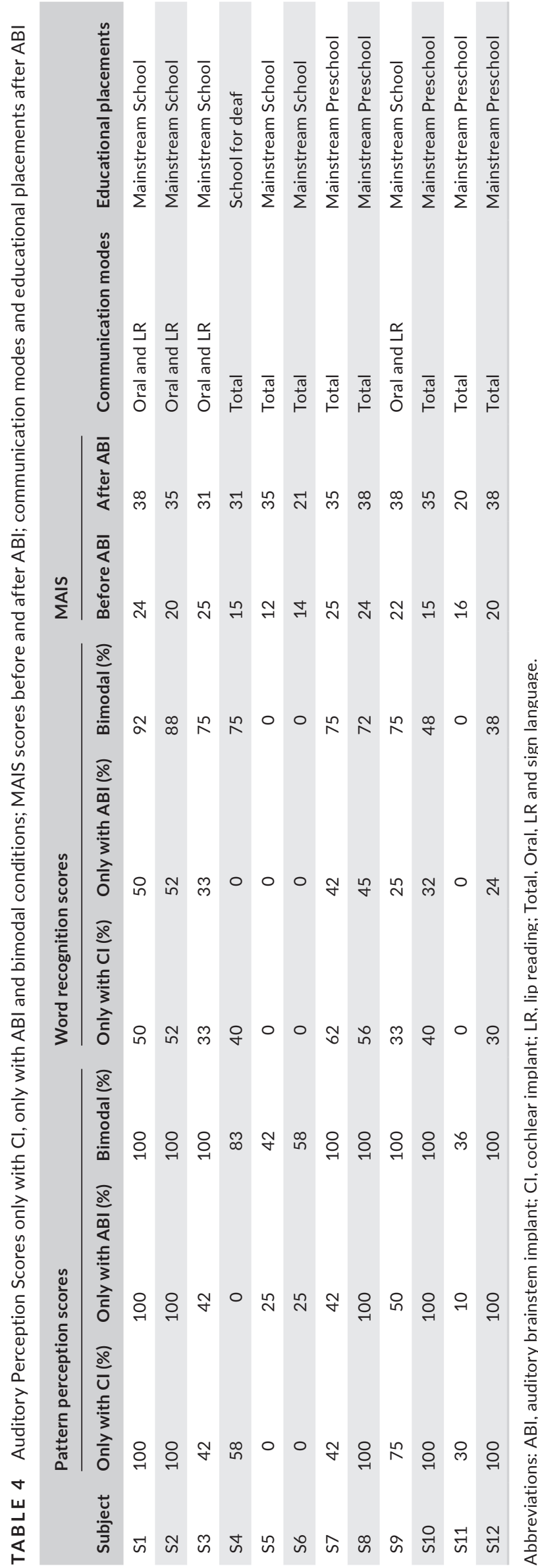

On the other hand, $A B I$ provides users with sound identification and development of open-set speech discrimination in patients with $\mathrm{CN}$ deficiency. ${ }^{4}$ In accordance with the literature, $12 \mathrm{Cl}$ only users in our series showed some progress with $\mathrm{Cl}$, but after a while, they reached a plateau. This finding may be related to the fact that stimulation of $\mathrm{CN}$ fibres that cannot be revealed clearly on the MRI may have provided input to the auditory brainstem, but this input was not adequate for appropriate stimulation at higher levels of the auditory pathway. As a solution for this suboptimal progress of $\mathrm{Cl}$ users with $\mathrm{CN}$ deficiency, contralateral $\mathrm{ABI}$ was considered as another option during the follow-up.

During the preoperative evaluation for decision-making between $\mathrm{Cl}$ and $\mathrm{ABI}$, we evaluated the audiological and radiological results together. In the preoperative audiological evaluation, it is important to perform subjective behavioural tests with inserted earphones. The behavioural tests provide us with the chance to see the auditory responses that we cannot get in objective tests such as $A B R$. The response of both ears can be assessed separately while using the inserted earphones, and it is then possible to determine which ear is better during the audiological evaluation. $\mathrm{Cl}$ should be recommended for that better ear with the presence of a response during behavioural testing and the presence of a hypoplastic $\mathrm{CN}$ or CVN on MRI. ABI can be recommended for the worse ear when we cannot get any response in audiological tests and cannot see any $\mathrm{CN}$ or CVN on imaging.

Another remedy for these patients may be the bilateral application of $\mathrm{Cl}$. In fact, it was reported that bilateral $\mathrm{Cl}$ provides more benefit for users with $\mathrm{CN}$ hypoplasia compared to unilateral $\mathrm{Cl}$ in CVN deficiency. ${ }^{18}$ Considering the limited benefit of $\mathrm{Cl}$ alone for these patients, $\mathrm{ABI}$ could provide better outcomes. An option in this case may be the removal of the $\mathrm{Cl}$ electrode and $\mathrm{ABI}$ application to the same side. Colletti et al (2013) presented outcomes of 21 children diagnosed with possible $\mathrm{CN}$ aplasia/hypoplasia and CAP scores of less than 2 who had a $\mathrm{Cl}$ in another centre. Due to their suboptimal progress, $\mathrm{ABI}$ was planned on the same side with $\mathrm{CI}$. During surgery, they observed that none of the children had a $\mathrm{CN}$. After $\mathrm{ABI}$, CAP scores of the users were reported to be significantly better. This procedure described by Colletti et al, ${ }^{7}$ although successful, still provides unilateral stimulation. In our opinion, bilateral stimulation of the auditory pathways is the most important factor in a paediatric population with possible $\mathrm{ABI}$ indications. Therefore, in case of a confirmed hypoplastic $\mathrm{CN}$ or $\mathrm{CVN}$ on radiological imaging, keeping the $\mathrm{Cl}$ in place and applying $\mathrm{ABI}$ to the other ear would be a better approach. In fact, patients reported in our work showed improvement in language and auditory perception skills after $A B I$ surgery. For the greatest benefit, bimodal stimulation should be provided as soon as possible due to the brain plasticity. In our case series, the mean duration between $\mathrm{Cl}$ and $\mathrm{ABI}$ surgeries was found as 16 months. Depending on our clinical experience, contralateral $A B I$ should be done within 12-18 months after $\mathrm{Cl}$.

In fact, the importance of bilateral stimulation for paediatric patients with various inner ear malformations has been mentioned in the second consensus meeting of $\mathrm{ABI}$ in complex inner ear 
malformations. ${ }^{19}$ Improvement in language skills after the application of $\mathrm{ABI}$ for $\mathrm{Cl}$ users with inner ear malformations may be related to adequate stimulation of areas in higher auditory pathways, which were not optimally stimulated during $\mathrm{Cl}$ usage. This improvement could be increased in time with regular use and result in more favourable outcomes for users. It was also mentioned in the second consensus meeting that hearing thresholds with $A B I$ were between 30 and $60 \mathrm{~dB}$ in most patients with $\mathrm{ABI} .{ }^{19}$ In our case series, the hearing thresholds with $A B I$ were found to be similar to the $A B I$ consensus paper. In our paper presenting the long-term results of the $A B I$, it was found that better thresholds were associated with better CAP scores. ${ }^{20}$ Similar to the children with unilateral $A B I$, better hearing performance with $\mathrm{ABI}$ resulted in higher bimodal pattern perception scores for children with $\mathrm{Cl}$ and contralateral $\mathrm{ABI}$. Another positive prognostic factor affecting the auditory performance with $A B I$ was defined as chronological age and age at $A B I$ surgery in the present study. Age at $A B I$ activation was also found to be one of the most important prognostic factors in the same paper. $^{19}$

In the study of Peng et al, ${ }^{9}$ despite deteriorated auditory performance with $\mathrm{Cl}$ within time, $\mathrm{ABI}$ was indicated as the primary method of hearing in nine NF-2 patients with $\mathrm{Cl}$ and contralateral $\mathrm{ABI}$. Similar to our study, Friedmann et al reported performance with $\mathrm{ABI}$ and contralateral $\mathrm{Cl}$ in four paediatric patients and found that three out of four patients had better auditory perception performance in the bimodal condition. They concluded that bimodal stimulation contributes to the auditory performance of children with $\mathrm{CN}$ deficiency. ${ }^{10}$

The $\mathrm{Cl}$ and contralateral $\mathrm{ABI}$ can be used together safely and synergistically. After $A B I$ surgery, a relatively rare side effect was observed for Subject \#2. Three days after the ABI surgery, when the patient activated his $\mathrm{Cl}$ device for the first time since the $A B I$ surgery, he had an excessive FNS on the $\mathrm{Cl}$ side. This was remedied by decreasing the $\mathrm{C}$-levels globally on the $\mathrm{Cl}$ side. Later, after initial activation of the $A B I$, the same FNS was observed both with individual electrode stimulation and with live voice through $\mathrm{Cl}$. In order to remove this FNS on the $\mathrm{Cl}$ side, the pulse width of the stimulation was increased from 50 to 88 , and C-levels were decreased according to his responses. A possible reason for this problem may be the increased impedance values on the $\mathrm{Cl}$ electrode after $\mathrm{ABI}$ surgery.

\section{1 | Study limitations}

Even though the present study is the first and therefore the largest study of children with IEM using $\mathrm{Cl}$ and contralateral $\mathrm{ABI}$, the study sample is still too small to conclusively show the effect of the bimodal stimulation with $\mathrm{Cl}$ and $\mathrm{ABI}$. The present study is also limited by the heterogeneity of the study population and reported test results. Only the auditory performance data from before $A B I$ and the last follow-up visit were included in this study. In future studies, long-term results in large cohorts can be presented during the follow-up visits.

\section{5 | CONCLUSION}

$\mathrm{CN}$ hypoplasia presents a challenge in the decision-making process concerning the choice of $\mathrm{Cl}, \mathrm{ABI}$, or $\mathrm{Cl}$ and $\mathrm{ABI}$ together. In case of visible cochlear nerve with behavioural responses, $\mathrm{Cl}$ should be tried first. In cases of hardly visible cochlear nerve, we have observed that children implanted with $\mathrm{Cl}$ and contralateral $\mathrm{ABI}$ showed better performance when compared to either device alone. In some cases, contralateral procedure can be decided according to $\mathrm{Cl}$ performance. If there is a definite indication on one side, both $\mathrm{Cl}$ and $\mathrm{ABI}$ surgeries can be done simultaneously. Depending on the audiological and radiological results, bilateral stimulation should be advised for children with IEM and CN hypoplasia.

\section{CONFLICT OF INTEREST}

All authors declare that they have no conflict of interest.

\section{ORCID}

Merve Ozbal Batuk (D) https://orcid.org/0000-0003-4771-8127

Betul Cicek Cinar (D) https://orcid.org/0000-0001-5496-3708

\section{REFERENCES}

1. Owens D, Espeso A, Hayes J, Williams R. Cochlear implants: referral, selection and rehabilitation. Curr Paediatr. 2006;16(5):360-365.

2. Sennaroglu L, Saatci I. A new classification for cochleovestibular malformations. Laryngoscope. 2002;112(12):2230-2241.

3. Sennaroglu L. Cochlear implantation in inner ear malformations-a review article. Cochlear Implants Int. 2010;11(1):4-41. https://doi. org/10.1002/cii.416

4. Sennaroglu L, Colletti V, Manrique M, et al. Auditory brainstem implantation in children and non-neurofibromatosis type 2 patients: a consensus statement. Otol Neurotol. 2011;32(2):187-191.

5. Sennaroglu L, Sennaroglu G, Atay G. Auditory brainstem implantation in children. Curr Otorhinolaryngol Rep. 2013;1(2):80-91.

6. Colletti L, Colletti G, Mandalà M, Colletti V. The therapeutic dilemma of cochlear nerve deficiency: cochlear or brainstem implantation? Otolaryngol Head Neck Surg. 2014;151(2):308-314.

7. Colletti L, Wilkinson EP, Colletti V. Auditory brainstem implantation after unsuccessful cochlear implantation of children with clinical diagnosis of cochlear nerve deficiency. Ann Otol Rhinol Laryngol. 2013;122(10):605-612.

8. Yücel E, Aslan F, Özkan HB, Sennaroglu L. Recent rehabilitation experience with pediatric ABI users. J Int Adv Otol. 2015;11(2):110.

9. Peng KA, Lorenz MB, Otto SR, Brackmann DE, Wilkinson EP. Cochlear implantation and auditory brainstem implantation in neurofibromatosis type 2. Laryngoscope. 2018;128(9):2163-2169.

10. Friedmann DR, Asfour L, Shapiro WH, Roland JT Jr, Waltzman SB. Performance with an auditory brainstem implant and contralateral cochlear implant in pediatric patients. Audiol Neurotol. 2018;23(4):216-221.

11. Robbins AM, Renshaw JJ, Berry SW. Evaluating meaningful auditory integration in profoundly hearing-impaired children. Am J Otol. 1991;12:144-150.

12. Archbold S, Lutman M, Marshall D. Categories of auditory performance. Ann Otol Rhinol Laryngol Suppl. 1995;166:312-314.

13. Allen MC, Nikolopoulos TP, O'Donoghue GM. Speech intelligibility in children after cochlear implantation. Am J Otol. 1998;19(6):742-746.

14. Bradley J, Beale T, Graham J, Bell M. Variable long-term outcomes from cochlear implantation in children with hypoplastic auditory nerves. Cochlear Implants Int. 2008;9(1):34-60. 
15. Gray R, Ray J, Baguley D, Vanat Z, Begg J, Phelps P. Cochlear implant failure due to unexpected absence of the eighthnerve-a cautionary tale. J Laryngol Otol. 1998;112(7):646-649.

16. Shi Y, Li Y, Gong Y, Chen B, Chen J. Cochlear implants for patients with inner ear malformation: Experience in a cohort of 877 surgeries. Clin Otolaryngol. Surgery. 2019;44(4):702-706.

17. Coudert A, Vigier S, Scalabre A, Hermann R, Ayari-Khalfallah S Truy E. Analysis of inner ear malformations associated with a facial nerve anomaly in 653 children fitted with a cochlear implant. Clin Otolaryngol. 2019;44(1):96-101.

18. Oker N, Loundon N, Marlin S, Rouillon I, Leboulanger N, Garabédian EN. Bilateral implantation in children with cochleovestibular nerve hypoplasia. Int J Pediatr Otorhinolaryngol. 2009; 73(10):1470-1473.

19. Sennaroğlu L, Colletti V, Lenarz T, et al. Consensus statement: longterm results of $\mathrm{ABI}$ in children with complex inner ear malformations and decision making between $\mathrm{Cl}$ and $\mathrm{ABI}$. Cochlear Implants Int. 2016;17(4):163-171.

20. Sennaroglu L, Sennaroglu G, Yücel E, et al. Long-term results of $\mathrm{ABI}$ in children with severe inner ear malformations. Otol Neurotol. 2016;37(7):865-872.

How to cite this article: Batuk MO, Cinar BC, Yarali M, et al. Bimodal stimulation in children with inner ear malformation: One side cochlear implant and contralateral auditory brainstem implant. Clin Otolaryngol. 2020;45:231-238. https://doi. org/10.1111/coa.13499 